\title{
LUDWIG FEUERBACH
}

Gesammelte Werke

7 


\title{
LUDWIG FEUERBACH
}

\section{GESAMMELTE WERKE}

\author{
HERACSGEGEBEN VON
}

WERNER SCHUFFENH.IUER

7

AKADEMIE-VERLAG - BERLIN 1985 


\title{
LUDWIG FEUERBACH
}

\section{Theogonie}

\author{
nach den Quellen \\ des klassischen, hebraischen \\ und christlichen Altertums
}

3., gegenüber der 2. unveranderte Auflage

AKADEMIE-VERLAG - BERLIN

1985 
Bearbeiter dieses Bandes

W"OLFGANG HARICH

Redaktion dieser Auflage
Werner Schuffenhauer

Frschienen in Akademe-Verlag, DDR - 1086 Berlu, Leipuger ste 34

(C) Ahademie-Verlag Berlın 1985 (1969)

Lizenenummer $202 \quad 100 / 10 / 85$

Printed in the German Democratic Republic

Oftsetdruck und bucbbinderische Weterverarbestung

VEB Druckerel "Thomas Muntzer", s820 Bad Langensalıa

LST 0116

Bestellnummer $7900934(4042 / 7)$

02500 